\title{
The Challenge of Caring for the Severely Disabled
}

\author{
William L. Toffler, MD
}

Caring for the severely disabled is challenging. More than a dozen years ago, a colleague of mine left our group family practice to practice full-time geriatrics. His leaving had a great impact on me. He was quite skilled in caring for the disabled; I was not.

When he left, I assumed the care of a few of my colleague's group-home patients, at least for acute issues. Most could not speak for themselves. Many had rare and complex syndromes. In short, even as an experienced clinician, I was uncomfortable. Grasping the big picture seemed impossible in the time scheduled. When one of my disabled patients was wheeled into my office, I was not enthusiastic-I knew at once I would be late finishing my day.

Although I lacked eagerness, I did try to take whatever time was required. Eventually, my investment in time paid dividends. I grew more comfortable with my disabled patients' long-term needs. I began to enjoy caring for them, even simply interacting with them. Apparently, their caregivers noticed the changes in my attitude, because soon they began referring all of their group-home patients to me. I felt both flattered and uneasy. Even though I enjoyed the challenge, severely disabled patients still demanded additional time. Did I really want so much of my practice devoted to patients with such complex medical problems?

In short, no matter how experienced one is, caring for the severely disabled is challenging. Physicians, families, and caregivers can become tired, isolated, and even burnt out from shear exhaustion. Feelings of helplessness and isolation can, at times, be overwhelming for everyone, not to mention the disabled patient!

Submitted 7 October 2002.

From the Department of Family Medicine, Oregon Health \& Science University, Portland. Address reprint requests to William L. Toffler, MD, Department of Family Medicine, Oregon Health \& Science University, 3181 SW Sam Jackson Park Rd, Portland, OR 97239.
If caring for the severely disabled is challenging, caring for them when they are acutely ill can be extraordinarily demanding. Complex issues that otherwise might develop over years are compressed into days, even hours. At the same time, uncertainties and outcomes might not be resolved for months. Even then, one is often left with questions. Did we make the right decisions? Were our efforts worth it? How do we measure our success?

Clearly, each of these questions applies in the case of John, a 30-year-old man with Lesch-Nyhan syndrome reported in this issue of the fournal. ${ }^{1}$ What might otherwise have been a routine admission for urosepsis ultimately involved a myriad of complications requiring prolonged intensive care. John ultimately died on his 104th hospital day. Although John's complications were unwanted and regrettable, such a prolonged course could well have occurred in a patient without disabilities. Had his course occurred in an able person, his medical issues would be unlikely to merit the publication of a case report. Thus, it is legitimate to reflect on those elements of this case that make publication and critical review warranted.

To some degree the difficulties encountered can be attributed to the absence of an advance directive or a designated person with a durable power of attorney. Certainly, had an explicit directive to avoid (or stop) specific interventions been available, it might have assisted decision making at one or more junctures in his care. On the other hand, John's advance directive might well have been for full-care measures. If so, little about the course would have changed. In fact, such full treatment would be automatic for any person without such profound disabilities. Yet even at his best, John was profoundly disabled. As his complications increased, inevitably the question of futility arose.

So, when is care futile? When do interventions simply prolong the dying process, the inevitable end? Tough questions. I remember a baby with severe kidney problems born in a small hospital in Eastern Washington. Three hospitals in Portland 
(including my own) refused to accept the baby in transfer because they judged that caring for the baby would be futile. A physician at a fourth hospital did not and agreed to care for the child. Although the baby required life-flight and extensive treatment, he lived for 2 years. I still remember the joy in his parent's faces as they celebrated his first birthday-with more than 300 in attendance! What then is futile? Clearly, the call is subjective.

In John's case, 40 days into the hospitalization his brother (who also had Lesch-Nyhan syndrome) protested, "No more! Let him go to God." Obviously, John's brother was convinced any further care was futile. Yet, there were many subsequent occasions where John's condition improved. In fact, there was no way for either his brother or for the providers to be certain that the patient's condition was terminal. It was indeed possible that John could have regained his former level of function. Our inability to predict outcomes is well documented in the medical literature. ${ }^{2,3}$

Even though each issue raised by John's care is important and worthy of discussion, the core reason that John's case merits publication and deep reflection is that his story forces each of us to examine and expose our implicit assumptions and biases. In short, should we respond to an acute illness and complications in a person with profound disabilities in the same manner as we do in a person without such debility?

Today, the field of medicine wrestles with the pressures of increasing costs, government regulations, and the perception that health care resources are finite. The consensus would seem that we should avoid using valuable resources when there is no positive impact on the ultimate outcome. ${ }^{4,5}$ Rather, such resources should be used where benefit is clearly established. In fact, this principle is the cornerstone of the Oregon Health Plan (OHP), the first welfare health plan to ration health care prospectively and explicitly. ${ }^{6}$ At the same time, such utilitarian logic might undermine an equally important principle-the right to equal care regardless of disability (or social standing). Unfortunately, this principle (among other related principles) is at risk of being trumped by a disproportionate emphasis on cost. The potential for inherent conflicts of interest abounds. Who deserves what services? Who decides? For whom (or for what) is the physician an advocate?
Although it is tempting to be concerned about the distribution of health resources to the population at large (as the OHP does), decisions at the bedside should not be driven by cost concerns. Patients deserve a physician who is an unabashed advocate for their health and well-being, regardless of the cost, work, or time involved. Adjusting the level of intensity of care based on the degree of disability is discrimination at best, if not complete bigotry.

During a dark hour of the 20th century, physicians in Nazi Germany were commissioned to grant a mercy death to patients judged incurably sick by medical examination. ${ }^{7}$ Today, most of us shudder to think such euphemisms veiled the intentional killing (by physicians) of the mentally handicapped, the weak, and the disabled. At the same time, some scholars, such as Peter Singer at Princeton University, question the rights, even the humanity, of some disabled persons. ${ }^{8}$ Others believe that some persons (perhaps those such as John?) have a duty to die because of the cost and burden they impose on society. 9,10

Unfortunately, such bigotry is not the exclusive domain of a few academic elite. Treatment and care decisions are also influenced by biases of health care providers. A recent study of physician decision making suggests that they believe advanced age is a sufficient disability to justify withholding treatment. ${ }^{11}$ Whether conscious or unconscious, this clearly is discrimination based on age.

We are all aging. Furthermore, each of us either is or will become disabled (should we live long enough). Yet, our age or our individual debility, regardless of severity, can never negate our inherent worth.

On the contrary, coping with serious illness and disability can actually add to the dignity and satisfaction in our lives. Character can be deepened and relationships can be enriched during difficult life circumstances. For example, a recent study showed that many patients infected with the human immunodeficiency virus believe that life with their illness is better than it was before they became infected. ${ }^{12}$ This life change occurs, not in spite of illness or disability; it occurs because of it.

Enrichment of life as a result of illness or disability might seem obvious, but it seems forgotten in an era in which practical concerns outweigh human values. After all, caring for the severely disabled is not only challenging, it is costly! Yet, 
Lohiya and his co-authors are correct in their discussion of end-of-life care. That the United States can afford expensive care for its citizens ${ }^{1}$ was affirmed in a recent speech by President Bush, who said, "Our society has enough compassion, wealth, and love to care for mothers and their children, and to see the promise and potential of every life. In protecting the vulnerable and the weak, the imperfect and unwanted, you are affirming a culture of life."* Although his address was not specifically referencing the disabled, his words should strike a chord with every physician. We must rededicate our decision making to do what is best for the individual patient, not for the economic good of either the managed care system or the country.

Our society is the richest in the history of mankind. Whereas some pockets of poverty persist, our overall per capita income, our abundance of food, our discretionary time, material goods, technology, freedom, and capacity to travel are unprecedented. Despite the challenges and the (sometimes) extraordinary efforts needed to provide care to the disabled, I believe that we have knowledge, the skill, and the necessary resources to do so. The question of cost should be no more relevant in caring for the poor than it is for the wealthy.

We already have the resources. In essence, there is a way! As is often the case, the question becomes, Do we have the will? I, for one, hope so. I believe we can and should provide care for all of our citizens regardless of their class, their color, their religion, their economic status, or the severity of

${ }^{*}$ Remarks by President George W. Bush in signing the Born-Alive Infants Protection Act (HR 2175) during a trip to Pittsburgh, at the Pittsburgh Hilton, 5 August 2002. their disability. While caring for the severely disabled is indeed challenging, as physicians we must continue to be their advocates.

\section{References}

1. Lohiya GS, Tan-Figueroa L, Crinella FM. End-oflife care for a man with developmental disabilities. J Am Board Fam Pract 2003;16:xx-xx.

2. Christakis NA, Lamont EB. Extent and determinants of error in doctors' prognoses in terminally ill patients: prospective cohort study. BMJ 2000;320: $469-72$.

3. Christakis N. Death foretold: prophecy and prognosis in medical care. Chicago: University of Chicago Press, 2000.

4. Anderson JG, Harshbarger W, Weng HC, Jay SJ, Anderson MM. Modeling the costs and outcomes of cardiovascular surgery. Health Care Manag Sci 2002;5:103-11.

5. Reddy SS. Health outcomes in type 2 diabetes. Int J Clin Pract Suppl 2000;113:46-53.

6. Oberlander J, Marmor T, Jacobs L. Rationing medical care: rhetoric and reality in the Oregon Health Plan. CMAJ 2001;164:1583-7.

7. Barondess JA. Medicine against society. Lessons from the Third Reich. JAMA 1996;276:1657-61.

8. Singer PA. Practical ethics. 2nd ed. New York: Cambridge University Press, 1993:83-109.

9. Hardwig J. Is there a duty to die? Hastings Cent Rep 1997;27:34-42.

10. Corlett JA. Is there a moral duty to die? Health Care Analy 2001;9:41-63.

11. Johnson MF, Lin M, Mangalik S, Murphy DJ, Kramer AM. Patients' perceptions of physicians' recommendations for comfort care differ by patient age and gender. J Gen Intern Med 2000;15:248-55.

12. Tsevat J, Sherman SN, McElwee JA, et al. The will to live among HIV-infected patients. Ann Intern Med 1999;131:194-8. 